\title{
Developing Resources to Support Comprehensive Transfer Engineering Cur- ricula: Assessing the Effectiveness of a Hybrid Materials Science Course
}

\section{Dr. Erik N Dunmire, College of Marin}

Erik Dunmire is a professor of engineering and chemistry at College of Marin. He received his Ph.D. in Chemical Engineering from University of California, Davis. His research interests include broadening access to and improving success in lower-division STEM education.

\section{Dr. Amelito G Enriquez, Canada College}

Amelito Enriquez is a professor of Engineering and Mathematics at Cañada College in Redwood City, CA. He received a BS in Geodetic Engineering from the University of the Philippines, his MS in Geodetic Science from the Ohio State University, and his $\mathrm{PhD}$ in Mechanical Engineering from the University of California, Irvine. His research interests include technology-enhanced instruction and increasing the representation of female, minority and other underrepresented groups in mathematics, science and engineering.

\section{Prof. Nicholas P. Langhoff, Skyline College}

Nicholas Langhoff is an associate professor of engineering and computer science at Skyline College in San Bruno, California. He is also a co-investigator for multiple grant projects at Cañada College in Redwood City, California. He received his M.S. degree from San Francisco State University in embedded electrical engineering and computer systems. His research interests include technology-enhanced instruction, online engineering education, metacognitive teaching and learning strategies, reading apprenticeship in STEM, and the development of novel instructional equipment and curricula for enhancing academic success in science and engineering.

\section{Mr. Thomas Rebold, Monterey Peninsula College}

Tom Rebold has chaired the Engineering department at Monterey Peninsula College since 2004. He holds a bachelor's and master's degree in electrical engineering from MIT, and has been teaching online engineering classes since attending the Summer Engineering Teaching Institute at Cañada College in 2012.

\section{Eva Schiorring, Canada College}

Eva Schiorring has almost two decades of experience in research and evaluation and special knowledge about STEM education in community colleges and four-year institutions. Ms. Schiorring presently serves as the external evaluator for three NSF-funded projects that range in scope and focus from leadership development to service learning and experimentation with alternative delivery, including online lab courses. Ms. Schiorring is also evaluating a project that is part of the California State University system's new initiative to increase first year persistence in STEM. In 2014, Ms. Schiorring was one of the first participants in the NSF's Innovation-CORPS (I-CORPS), a two-month intensive training that uses an entrepreneurship model to teach participants to achieve scalable sustainability in NSF-funded projects. Past projects include evaluation of an NSF-funded project to improve advising for engineering students at a major state university in California. Ms. Schiorring is the author and co-author of numerous papers and served as project lead on a major study of transfer in engineering. Ms. Schiorring holds a Master's Degree in Public Policy from Harvard University. 


\title{
Developing Resources to Support Comprehensive Transfer Engineering Curricula: Assessing the Effectiveness of a Hybrid Materials Science Course
}

\begin{abstract}
A substantial percentage of engineering graduates, especially those from traditionally underrepresented groups, complete their lower-division education at a community college before transferring to a university to earn their degree. However, engineering programs at many community colleges, because of their relatively small scale with often only one permanent faculty member, struggle to offer lower-division engineering courses with the breadth and frequency needed by students for effective and efficient transfer preparation. As a result, engineering education becomes impractical and at times inaccessible for many community college students. Through a grant from the National Science Foundation Improving Undergraduate STEM Education program (NSF IUSE), three community colleges from Northern California collaborated to increase the availability and accessibility of the engineering curriculum by developing resources and teaching strategies to enable small-to-medium sized community college engineering programs to support a comprehensive set of lower-division engineering courses. These resources were developed for use in a variety of delivery formats (e.g., fully online, online/hybrid, flipped face-to-face, etc.), providing flexibility for local community colleges to leverage according to their individual needs. This paper focuses on the development and testing of the resources for an introductory Materials Science course with 3unit lecture and 1-unit laboratory components. Although most of the course resources were developed to allow online delivery, the laboratory curriculum was designed to require some limited face-to-face interaction with traditional materials testing equipment. In addition to the resources themselves, the paper presents the results of the pilot implementation of the course during the Spring 2015 semester, taught using a flipped delivery format consisting of asynchronous remote viewing of lecture videos and face-to-face student-centered problemsolving and lab exercises. These same resources were then implemented in a flipped format by an instructor who had never previously taught the course, at a community college that did not have its own materials laboratory facilities. Site visits were arranged with a nearby community college to afford students an opportunity to complete certain lab activities using traditional materials testing equipment. In both courses, student surveys and interviews were used to assess students' perceptions of the effectiveness of the course resources, their use of these resources, and their overall satisfaction with the course. Additionally, student performance on assessments was compared with that of traditional lecture delivery of the courses in prior years.
\end{abstract}

\section{Introduction}

There is widespread recognition of the importance of STEM education for the future economic welfare of the United States, as well as of the role that 2-year colleges such as the California Community College (CCC) system can play in this effort. ${ }^{1,2}$ However, one challenge faced by many $\mathrm{CCC}$ engineering students is a lack of adequate access to lower-division engineering courses that are needed for transfer to public university programs in the state. ${ }^{3}$ With the exception of a few very large community colleges, most of the 112 colleges in California can 
only offer at most one section of each engineering course per year, and more than half of the colleges are unable to maintain even this level of access for their students.

To help increase the availability of lower-division engineering courses around the state, the Joint Engineering Program (JEP) was created, developed initially through a grant from the National Science Foundation and later supported by a grant from the US Department of Education. JEP has promoted the partnership of 27 community colleges across California, by aligning curriculum, sharing teaching resources and best practices, and helping students to access required engineering courses, often via online offerings at partner institutions. One persistent challenge, however, has been a lack of availability of quality online lab courses in engineering. As a result, Cañada College collaborated with College of Marin and Monterey Peninsula College to develop and obtain NSF support for the Creating Alternative Learning Strategies for Transfer Engineering Programs (CALSTEP), which is aimed at developing lab courses that can be offered online, or with limited face-to-face interaction. The courses developed include Introduction to Engineering, Engineering Graphics, Materials Science, Circuits, and MATLAB Programming.

In planning the new initiative, the three colleges agreed that they would develop lab courses that emphasized inquiry-based approaches requiring authentic problem-solving and student interaction, in an effort to enhance learning relative to many existing online and face-to-face lecture courses. Educational research has often shown that passive instructor-centered lecturing is less effective than approaches that actively engage students in the learning process. ${ }^{4,5}$ This is particularly true in engineering because of its emphasis on developing higher-order problem solving skills. For example, studies of introductory materials science students have demonstrated that the more constructive and interactive the student engagement is, the greater the learning gains. ${ }^{6,7}$

In fact, this realization has led to the increasing use of "flipped classroom" models for face-toface engineering instruction, wherein students are introduced to new course content outside the classroom through assigned readings, lecture videos, etc., and use class time to engage in more student-centered exploration of their knowledge and abilities. ${ }^{8,9}$ Many of the same resources developed for quality online instruction, such as recorded video content, computer-based tutorials, real-time assessment and feedback, student-led inquiry and discussions, individual and team problem-solving activities, etc., can be used to support flipped-classroom instruction. In both cases, an important advantage of these student-centered approaches is that they more easily accommodate a group of students with diverse preparation and ability, allowing the instructor to address the individualized learning needs of all the students in the class.

An additional benefit of a flipped classroom approach is that it has the potential to further address the access issue described above. Because of the more individualized approach to learning that takes place during class, it may be possible to co-list two or more low-enrolled courses, effectively combining their enrollments. Such class sessions could also be used to provide support to students in online courses, creating what might be called an "emporium" model. If successful, even a college that has a fairly small engineering program could use this approach to increase the breadth and frequency of its engineering offerings, thereby increasing access and flexibility for students in their academic planning and progress toward transfer. 
As a first step toward development of such an emporium model, College of Marin has begun to convert all of its engineering courses to flipped approaches. After testing and refining the curriculum and resources in each course, the college will begin to experiment with the combined-course approach.

The focus of this paper is the development of the resources for the Materials Science course, its pilot implementation at College of Marin in Spring 2015, and its subsequent implementation in Fall 2015 at Monterey Peninsula College by an instructor who had never previously taught the course.

\section{Development of Hybrid Materials Science Curriculum}

The development of curriculum and resources for the materials science course in this study was guided by a particular set of objectives and constraints:

A. Any course using the curriculum should articulate with the recently approved statewide course descriptor for ENGR 140B Materials Science and Engineering published on the course identification numbering system (c-id) website at https://c-id.net/view final.html. This descriptor specifies a 4-unit (3-unit lecture and 1-unit lab) course workload, prerequisite completion of one semester general chemistry and one semester calculus-based physics, a list of 20 content topics, and 6 general course learning objectives.

B. The course lecture resources should be flexible for use by a variety of instructors (novice and experienced) in a variety of delivery formats (e.g., flipped, online, blended). In particular, although the initial implementation and testing of the curriculum was in a "traditional" flipped format, future implementations were planned in which students from two or more different courses would be simultaneously performing student-centered activities under the guidance of a single instructor.

C. As with all of the lab curricula in the CALSTEP project, the lab should aim to achieve the thirteen objectives for engineering educational laboratories defined by the ABET/Sloan Foundation effort. ${ }^{10}$

D. In order to make the course suitable for delivery in the emporium approach, in an online/hybrid approach, or by institutions that lack materials testing equipment, the lab curriculum should require a minimum number of on-campus experiments in a traditional materials testing lab. At the same time, some exposure to such equipment was needed to satisfy objectives $\mathrm{A}$ and $\mathrm{C}$ above.

The course curriculum was developed by a community college instructor with a background in chemical engineering. He has taught the materials science course for the past 14 years in a traditional lecture format, but has taught other courses in engineering and chemistry using synchronous and asynchronous online delivery methods. During development, input was solicited from an advisory board with representation from all segments of California public higher education, and which included faculty with extensive experience teaching introductory materials science courses.

Some perceived challenges in developing a flipped curriculum for the Materials course are that, relative to most other engineering courses, there is greater conceptual depth, the scaffolding of 
concepts is less linear and more iterative, and understanding often relies on abstract atomic or microscopic-level concepts that remain unclear for many students even after completing the prerequisite chemistry and physics courses.

After considerable effort was dedicated to reviewing available resources, the instructor determined that most of the publicly available online lecture content for Materials seemed nonideal for meeting the objectives, either because it was poorly aligned with the content requirements of the course, or because the format seemed suboptimal for student learning. Because there was some disagreement as to which formats for pre-recorded lecture material are optimal in this application (for students and for the instructor), a variety of video formats was intentionally selected in order to investigate student preferences. In addition, the instructor used a screencasting approach to develop some video content (6 lessons each of 1-2 hour total duration, divided into 10-20 min modules), which supplemented the existing content that had been identified.

For in-class activities, 11 problem sets were developed to explore content in a team setting, as well as 12 brief formative assessments for key learning concepts, in addition to the lab curriculum. The set of experiments for the Materials course was chosen both to reinforce concepts addressed in the lecture component of the course, and also to achieve the 13 engineering lab learning objectives. Many of the labs were designed for possible at-home completion in an online or hybrid delivery of the course. These labs did address some of the 13 lab objectives to a limited extent, but they primarily involved the use of physical and virtual models, as well as testing of materials using qualitative and/or crude quantitative methods, in order to reinforce and explore terminology and concepts addressed in the lecture component of the course. Some labs also required analysis of actual experimental data that was supplied by the instructor, introducing not only the relevant data analysis tools and techniques, but also concepts of uncertainty analysis and limitations in the applicability of theoretical models. The lessons learned in these earlier labs served as an important foundation for the more involved labs later in the course that were designed for face-to-face completion by students in a future hybrid delivery of the course. A single 3-part brass lab series addressed all 13 lab learning objectives to some degree, and in fact was perceived to be adequate as the only in-person lab requirement by several members of the advisory board. This approach would simplify an online/hybrid delivery of the course for many community colleges, since in theory it could be completed in one or two fullday sessions.

A complete description of the curriculum, including course objectives, topics covered, and descriptions of the lab experiments and learning objectives, can be found at http://www.canadacollege.edu/nsf-iuse/.

\section{Implementation 1 by the Curriculum Developer}

\section{Institutional and Class Demographics}

College of Marin, located near San Francisco, CA, is a member of the California Community College (CCC) system. During the 2014-2015 academic year, the college enrolled 9,317 students, of whom $46 \%$ are white and $30 \%$ are Hispanic. As with all CCCs, College of Marin 
$(\mathrm{COM})$ is an open-enrollment institution. COM's Engineering program is a small transfer program that offers a comprehensive set of lower-division engineering courses needed for transfer to most four-year Engineering programs in CA public universities, a feat achieved by approximately 10 to 20 COM Engineering students each year. The Spring 2015 class that is the subject of this study consisted of 16 students, of whom $75 \%$ were white and $87 \%$ were male.

\section{Course Structure}

The class met twice per week for 3-hour sessions. Traditionally, one of these sessions was designated for "lecture" while the other was for "lab"; however, these distinctions were blurred in the flipped approach. Students were instructed that before class time, they should complete assigned reading from the textbook and watch a lecture module selected by the instructor. Students then used class time to complete group discussion and problem-solving exercises. To evaluate student preferences regarding video formats, students completed a survey of their impressions after viewing each lecture module, as detailed in the Results section below. Students also completed brief in-class quizzes that served as (1) an incentive to complete required textbook reading or video viewing, (2) an incentive to arrive on time to class, and (3) an assessment tool to gauge understanding of key concepts. The flipped approach to the course permitted more class time than usual to be dedicated to hands-on laboratory activities, allowing students to explore materials processing, testing and analysis in greater depth. In addition to a comprehensive final exam at the end of the course, there were two exams to assess student learning at roughly the one-third and two-thirds points in the course.

\section{Assessment Instruments}

In order to compare student learning in the flipped course to that of students in the previous lecture version of the course, students took the same final exam that had been administered the previous four years (Spring 2011 through Spring 2014). The final exam consists of conceptual and quantitative problems in a variety of formats (e.g., multiple-choice, matching, short answer, open-ended), covering the full range of topics addressed in the course, and including some questions that require students to apply knowledge to solve problems that were never specifically discussed.

To evaluate the learning gains made by students in the course, and to serve as a baseline for future comparisons, two different assessments were administered at the beginning ("Pre") and at the end ("Post") of the course. One of these assessments was the Materials Concept Inventory (MCI), a 30-question multiple-choice assessment instrument developed by faculty at Arizona State University and Texas A\&M University to measure conceptual understanding of topics in introductory materials science courses. ${ }^{11}$ The second assessment, developed in house, consisted of a small subset of traditional final exam questions in the course that were more applied in nature and not fully addressed by the MCI. These questions included materials classification and property ranking exercises, as well as crystallography, stress-strain, and phase diagram analysis problems.

In order to evaluate preferences regarding video lesson formats, students were asked to complete a video survey for each lesson. The survey asked students to report the length of time spent 
watching each lesson, to rate their ability to maintain focus and their level of understanding of the content, and to report on what they liked best and least about each lesson.

In order to evaluate overall attitudes about the course experience, the project researcher administered written surveys to all students, and conducted follow-up 20-minute interviews with the instructor and a representative subset of students.

\section{Results of Implementation 1}

\section{Evaluation of Student Performance}

Of the 16 students who enrolled in the course, 13 persisted to the end of the semester and took the final examination, and all but one of these students earned a passing grade in the course. As shown in Table 1, this $75 \%$ success rate was not significantly different from that of classes taught the previous four years in a traditional lecture format (mean of $83 \%$, range of $71 \%$ to $100 \%$ ). Similarly, although the final exam average of $86 \%$ for the flipped class was higher than the average in any of the previous classes (mean of $82 \%$, range of $78 \%$ to $84 \%$ ), this difference was not statistically significant. Several factors may explain why the flipped class did not demonstrate the improved performance exhibited in some other studies that compared active learning to traditional lecture. First, the small sample sizes in this study make demonstration of statistical significance difficult to achieve, even when effects may be present. Second, as reflected in Table 1, the flipped class was approximately double the size of the prior lecture classes, and so the increased class size may have partially counteracted some of the benefits gained by an active learning approach. Finally, and perhaps most importantly, most prior studies on the benefits of active learning have been based on large university classes; it is possible that a traditional lecture-based approach by an experienced instructor is as effective (or nearly so) in very small classes, because of the higher level of engagement between students and instructor in such an environment.

Table 1. Comparison of performance by students in the flipped class and in the traditional lecture classes during the previous four years.

\begin{tabular}{|c|c|c|c|c|}
\hline \multirow[b]{3}{*}{ Students Enrolled } & \multicolumn{2}{|c|}{$\begin{array}{c}\text { Flipped } \\
\text { Spring } 2015\end{array}$} & \multicolumn{2}{|c|}{$\begin{array}{c}\text { Lecture } \\
\text { Spring } 2011 \text { - Spring } 2014\end{array}$} \\
\hline & Mean & Std. Dev. & Mean & Std. Dev. \\
\hline & 16 & & 7.8 & 1.0 \\
\hline Students Retained & 13 & & 7.0 & 1.4 \\
\hline Students Passed & 12 & & 6.5 & 1.7 \\
\hline Success Rate & $75 \%$ & & $83 \%$ & $14 \%$ \\
\hline Final Exam & $86 \%$ & $10 \%$ & $82 \%$ & $11 \%$ \\
\hline
\end{tabular}

*The differences in success rates and final exam scores between the flipped class and prior lecture classes were not statistically significant. 
Table 2 summarizes the learning gains made by the 11 students who completed both the pre and post assessments. Students on average answered 52\% of the questions correctly on the in-house pre-test, with higher scores (average 70\%) on the classification and ranking exercises, and lower scores (average 18\%) on the applied analysis problems. After the course, students on average answered $90 \%$ of these questions correctly, reflecting an average increase of $38 \%$. This corresponds to an average normalized (Hake) gain ${ }^{12} \mathrm{G}$ of 0.79 ; in other words, students achieved on average $79 \%$ of their possible learning gain on this assessment instrument.

As is customary with concept inventories, learning gains were somewhat more modest as measured by the MCI, with average scores increasing from $44 \%$ pre to $61 \%$ post, an average increase of $18 \%$, and a normalized gain $\mathrm{G}$ of 0.32 . Although this indicates that only one-third of the potential gain in conceptual understanding was realized on average, these results compare favorably with those reported by others for the MCI. During initial development and testing of the MCI, Krause et al. reported gains of $10 \%$ to $15 \%$ for traditional lecture classes, but $37 \%$ for an active-learning class taught by the MCI author. Similarly, a subsequent study by Jordan for 7 sections (approximately 210 students) of an introductory materials science course at Louisiana Tech University reported an average gain of $7 \%$ from $32 \%$ pre to $39 \%$ post. ${ }^{13}$ As pointed out in this latter study, some questions on the MCI address topics that are not emphasized in some materials science courses; moreover, robust misconceptions assessed by some MCI questions prove resistant to change, even when active learning approaches are employed.

Table 2. Learning gains for Spring 2015 students in flipped course as measured by pre-course and post-course assessments, which included a custom set of materials analysis problems as well as the standardized Materials Concept Inventory.

\begin{tabular}{|crrrrr|}
\hline & & Pre-course & Post-course* & Change & $\mathrm{G}^{* *}$ \\
\cline { 3 - 6 } Analysis & Mean & $\mathbf{5 2 \%}$ & $\mathbf{9 0 \%}$ & $\mathbf{3 8 \%}$ & $\mathbf{0 . 7 9}$ \\
Problems & Std. Dev. & $10 \%$ & $7 \%$ & $11 \%$ & 0.12 \\
\hline Concept & Mean & $\mathbf{4 4 \%}$ & $\mathbf{6 1 \%}$ & $\mathbf{1 8 \%}$ & $\mathbf{0 . 3 2}$ \\
Inventory & Std. Dev. & $12 \%$ & $12 \%$ & $12 \%$ & 0.14 \\
\hline
\end{tabular}

*Post-course scores were significantly higher than pre-course scores on both assessments $(\mathrm{p}<0.001)$. **Normalized gain $\mathrm{G}=($ Post - Pre $) /(100 \%-$ Pre $)$

\section{Results of Student Video Surveys}

As mentioned previously, students were expected before each class to watch an online lecture module selected by the instructor. After viewing each lecture module, students completed an anonymous survey of their impressions, including the amount of time they spent watching the module, a rating (1-5) of how well they were able to maintain focus, a rating (1-3) of how well they understood the content, and comments regarding what they liked best and least about each module. Analysis of reported viewing times demonstrated substantial variation among students, with 15\%-40\% of respondents reporting zero minutes of viewing for each lesson, and a similar percentage reporting viewing times in excess of the total actual lesson time, explained by the majority of respondents who indicated repeatedly watching some portions of each lesson. One 
interesting finding was that for lessons recorded by the course instructor, $61 \%$ of respondents on average reported watching the entire lesson, while only $33 \%$ on average reported doing so for lessons by some other presenter. This could indicate that students thought, perhaps justifiably, that the course instructor's presentations would better prepare them to complete the course assignments and exams.

The differences among the video lesson formats were categorized according to 5 dichotomous variables, as indicated in Figure 1 below. Results of video ratings were mostly corroborated by student comments regarding their preferences. Students preferred lessons that were broken into shorter modules (the shorter the better) and had a pronounced dislike for recordings of live classroom lectures. They also indicated a slight preference for lectures by their own course instructor over those of nearly all other presenters, and for videos where camera footage of the presenter was visible in a portion of the screen. One interesting anomaly was that students expressed in their comments a preference for voice-over slide presentations (due to efficiency of navigation) as compared to videos, but on average rated these presentations lower in terms of both ability to maintain focus and level of comprehension. In terms of what students liked least, a majority of responses to nearly every lesson were "too long" and "too slow." The one exception was a module on diffusion by Patrick Shamberger of Texas A\&M, which consisted of a small number of brief fast-paced videos in YouTube, which has a video player that allows even higher playback speed options (anecdotally, most students prefer $1.5 \mathrm{x}$ or $1.75 \mathrm{x}$ for instructional video).

\section{Average Ability to Focus} (1 = Not at all, 5 = Full Attention)

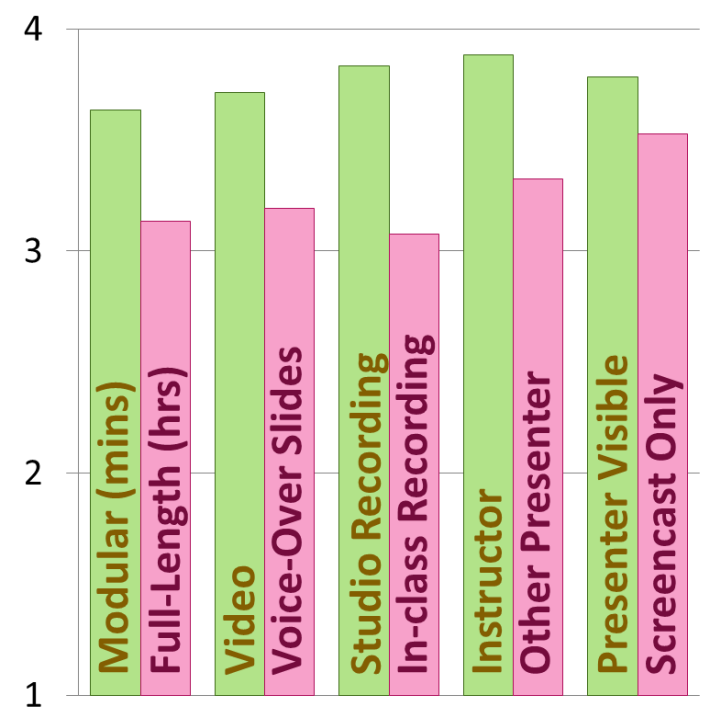

Average Comprehension

(1 = None, 3 = Full)

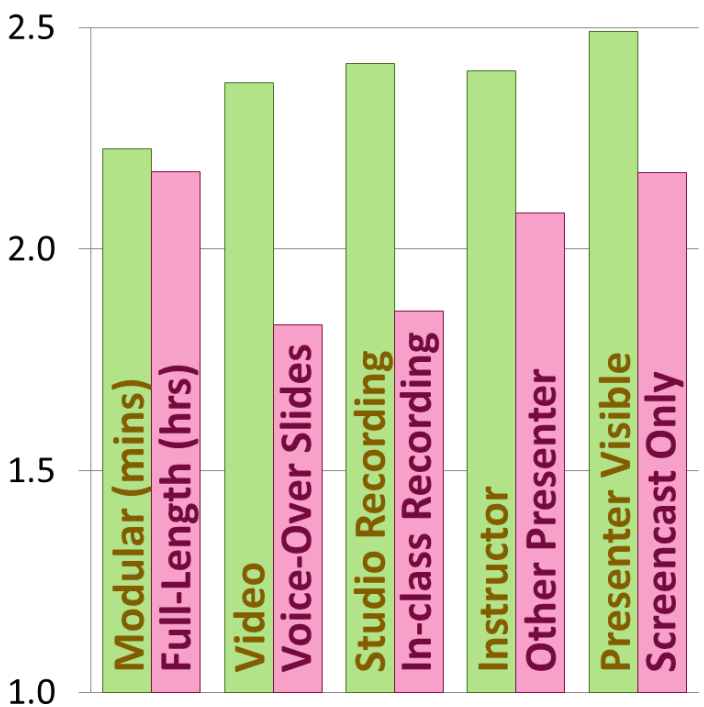

Figure 1. Average student ratings of (a) their ability to focus while watching each video lesson $(1=$ Not at all, $5=$ Full attention $)$ and (b) their understanding of the content in each lesson $(1=$ None, 2 = Some, $3=$ Full), categorized according to 5 dichotomous video format variables, as explained in the text. 


\section{Results of Student Course Surveys}

In the course survey and interviews, students expressed high levels of satisfaction with the laboratory component of the course, but less enthusiastic responses to the flipped approach. Nearly all students indicated that the lab was strongly connected to the lecture content (100\%), helped them understand course concepts better (92\%), and taught skills not otherwise covered in the lecture component (93\%). Although some students found the labs challenging and time consuming, most students listed the lab among the things they liked best about the course, commenting that the labs were "interesting" and "in-depth," and in one case expressed a desire for "even more labs."

Students' overall attitudes about the flipped approach were mixed - when asked whether they would recommend taking the class flipped to one of their friends, responses indicated that only $38 \%$ would, while $23 \%$ would not, and the rest were not sure. When asked to rate (1-5) which resources or activities in the course contributed the most to their learning, students gave high ratings ( 4 or 5 ) to mini-lectures from the instructor (86\%), hands-on lab activities (79\%), and inclass problem exercises $(64 \%)$. They gave low ratings ( 1 or 2 ) to the in-class quizzes $(72 \%)$, watching videos (43\%), and reading the textbook (43\%). Students also expressed very positive reactions in their ratings and comments toward working as a team in both lab and problemsolving activities. Most of the negative comments related to the videos, and reinforced the preferences expressed in the individual video surveys above. Nearly half of the survey respondents indicated a desire for "more lectures" in class.

In short, students expressed high satisfaction with activities that took place during class and low satisfaction with activities they were expected to complete outside of class. Students' responses to questions about their time commitment to the course provides further insight into this issue. In written surveys and interviews, many students acknowledged that they had learned a great deal in the course, but complained of the extensive time commitment required. However, when asked to estimate the total time spent inside and outside of class working on the course, the median value reported was 9 hours per week. Given that this was a 4-unit lab-based course with 6 hours per week of scheduled class time, the average 3 hours per week that students invested outside class would not be deemed "extensive" by most engineering faculty. In fact, official guidelines for hours and credit in CCC courses define a unit of credit as corresponding to approximately 3 hours per week of student effort, and acknowledge that STEM courses, especially those with lab components, have traditionally exceeded this multiple. ${ }^{14}$ In other words, while the institution deems 12 hours per week to be a nominal (or even minimal) time investment for the course, students on average perceived 9 hours per week as onerous. This discrepancy between student and instructor expectations of course workload may help to explain why some students experienced difficulty and expressed dissatisfaction with completing the out-of-class activities.

It is worth noting that the challenges encountered by students with the flipped approach in this course may depend in part upon the complex conceptual nature of the course content. For example, in a MATLAB programming course taught the same semester by the same instructor (and including some of the same students) using an identical approach, student reactions to the course were overwhelmingly positive, with $76 \%$ of students saying they would, and only $6 \%$ (1 student) saying they would not, recommend the flipped course to their friends. ${ }^{15}$ 


\section{Implementation 2 at a Different Institution}

Monterey Peninsula College (MPC), located on the central coast of CA, is a member of the California Community College (CCC) system. During the 2014-2015 academic year, the college enrolled 14,578 students, of whom $47 \%$ were white and $31 \%$ were Hispanic. MPC, like COM, has a small Engineering transfer program that offers a comprehensive set of lower-division engineering courses needed for transfer. The Fall 2015 class that is the subject of this study consisted of 19 students, of whom $50 \%$ were white and $77 \%$ were male.

An adjunct instructor who was assigned to teach the Materials course had to withdraw during the first week of the semester due to a family emergency. The full-time Engineering instructor at MPC stepped in to teach the course, despite already having a full teaching load and never having taught the course previously. His decision to teach the course was based solely on the fact that most of the 19 enrolled students needed the course to successfully transfer in a timely manner. The instructor was able to at the last minute hire as a teaching assistant for the course, a recent UCLA graduate, who had previously been an MPC student.

The MPC course was taught using the curriculum developed at COM, along with supplements created by the MPC instructor. Because of scheduling availability, however, students only met once per week for a single 4.5 -hour session. Students were expected to complete both the lecture viewing and the problem sets outside of class, and to use class time primarily for completing the labs, with some time available for assistance with the problem sets. One additional challenge in the course was that MPC did not have materials lab facilities, and had arranged to visit another CALSTEP community college (Cañada College) to use their facilities for completing the Brass Lab experiment. The other 11 lab assignments in the course were completed at MPC, and emphasized qualitative, modeling, and virtual approaches for concept exploration, combined with analysis of data from actual materials testing experiments.

In order to compare student learning in the Fall 2015 MPC course to that in the Spring 2015 COM course, students were given the same pre and post $\mathrm{MCI}$ and analysis problem assessments, as well as the same course final exam.

In order to evaluate overall attitudes about the course experience, the project researcher administered written surveys to all students, and conducted follow-up interviews with the instructor, the teaching assistant, and a subset of students.

\section{Results of Implementation 2}

\section{Evaluation of Student Performance}

Of the 19 students who enrolled in the course, 16 persisted to the end of the semester, and 15 received passing grades. Of these, 13 students completed both pre and post assessments. Table 3 compares the performance of Fall 2015 MPC students with that of Spring 2015 COM students. Class sizes and demographics appeared fairly comparable between the two groups, and there were no significant differences in pre-course scores on either assessment. Post-course scores and gains were significantly higher among the COM group, as were final exam scores. MPC students 
demonstrated significant learning gains on the in-house analysis problems, and acceptable mastery of the material on the course final exam ( $74 \%$ average), but showed no significant average gain in the types of conceptual understanding measured by the MCI.

Table 3. Comparison of performances by Spring 2015 COM students and Fall 2015 MPC students.

\begin{tabular}{|l|rr|rr|}
\hline \multicolumn{1}{c}{} & \multicolumn{2}{c}{ COM Spring 2015 } & \multicolumn{2}{c|}{ MPC Fall 2015 } \\
\cline { 2 - 5 } Analysis Pre & $\mathbf{5 2 \%}$ & $10 \%$ & $\mathbf{5 6 \%}$ & $10 \%$ \\
Analysis Post* & $\mathbf{9 0 \%}$ & $7 \%$ & $\mathbf{6 9 \%}$ & $9 \%$ \\
Analysis Change* & $\mathbf{3 8 \%}$ & $11 \%$ & $\mathbf{1 3 \%}$ & $12 \%$ \\
\cline { 2 - 5 } MCl Pre & $\mathbf{4 4 \%}$ & $12 \%$ & $\mathbf{4 2 \%}$ & $14 \%$ \\
MCl Post* & $\mathbf{6 1 \%}$ & $12 \%$ & $\mathbf{4 6 \%}$ & $11 \%$ \\
MCl Change* & $\mathbf{1 8 \%}$ & $12 \%$ & $\mathbf{4 \%}$ & $11 \%$ \\
Final Exam* & $\mathbf{8 6 \%}$ & $10 \%$ & $\mathbf{7 4 \%}$ & $10 \%$ \\
Students Enrolled & $\mathbf{1 6}$ & & $\mathbf{1 9}$ & \\
Students Retained & $\mathbf{1 3}$ & & $\mathbf{1 6}$ & \\
Students Passed & $\mathbf{1 2}$ & & $\mathbf{1 5}$ & \\
Success Rate & $\mathbf{7 5 \%}$ & & $\mathbf{7 9 \%}$ & \\
\hline
\end{tabular}

*Post scores, gains, and final exam scores were significantly higher for COM than MPC $(\mathrm{p}<0.001)$.

\section{Results of Student Course Surveys}

As reflected by student responses to the course survey and interviews, students at MPC experienced more difficulty and were less satisfied with the course than the COM students. Only $14 \%$ of respondents would, while $71 \%$ would not, recommend to a friend that they take the class in its present format. Some of the key challenges students reported experiencing related to difficulty in understanding how to complete the labs, insufficient familiarity with how to use spreadsheet software (e.g., Excel) to analyze data, and the large time commitment required to be successful in the course. Overall, these students went through the class feeling confused and struggling much of the time. By contrast, the student interviews found a high level of satisfaction with the overall course experience among a smaller group of students who were highly selfmotivated and persistent in their determination to master the material. These students reported that they had learned a tremendous amount from this class and had completed the course feeling that while the experience had been extremely time-consuming and difficult, it was also worthwhile.

Interviews with the instructor and teaching assistant revealed that they found the course difficult to teach, struggled with some of the lab assignments, and spent more time preparing for the class than they had expected. The instructional team also noted that many students arrived to class 
without adequate preparation, often not having read the lab handout, and therefore feeling lost given the student-centered nature of the curriculum.

On the positive side, MPC students reported higher satisfaction than had COM students with the online video lessons, with $73 \%$ of respondents rating the videos as effective for helping them understand the material. Some updates had been made to the video content between the two classes, replacing most of the longer video lectures with brief modular YouTube videos. Although this appeared to improve students' ability to use the videos as a learning resource, some students still felt that having videos from different presenters and institutions made it harder for them to understand the material. Many students indicated that the videos recorded by the COM professor and "the Howdy guy" (Professor Shamberger, Texas A\&M) seemed to most closely align with the learning objectives needed for the problem sets, labs, and exams.

Additionally, although students reported difficulty in completing the qualitative, virtual, modeling, and data analysis labs that were conducted at MPC, they felt that the "field trip" to Cañada College to complete the brass lab was the highlight of the course. In fact, when asked to rate how much they learned from each activity in the course, $90 \%$ of students rated this field lab experience the highest. In interviews, students emphasized how rewarding it was to apply the theoretical concepts from the course to the processing and testing in a real materials lab.

As with COM students, MPC students' comments about the large workload for the course seem at odds with their survey estimates of actual time spent. Estimates of total time spent on the course inside and outside class ranged from 5 to 10 hours per week, with a median of 7 hours. The employment status of students in the class may help to explain why many were unable to dedicate more time to the course even though they were struggling- $73 \%$ were employed more than 12 hours per week, and 40\% more than 20 hours per week. Given other obligations in these students' lives (e.g., other classes, family, etc.), they may not have had the flexibility to increase their time investment for the class. However, when asked how many hours students felt they would need to spend on the course in order to do as well as possible, the median value rose to only 10 hours, still less than the nominal 12 hours per week expected for a 4-unit course. Given that most community college students are underprepared for the courses in which they enroll, this discrepancy in workload expectations is likely to undermine student success in the course as currently designed.

\section{Conclusions and Future Plans}

The pilot implementation of the Materials curriculum at College of Marin, delivered in a flipped approach by the curriculum designer, was reasonably successful. Students demonstrated substantial learning gains according to multiple measures and achieved the learning outcomes in the course. Moreover, they found the lab experience highly rewarding, not only because it reinforced and contextualized the lecture content, but also because it conferred additional knowledge and skills beyond that covered in the text, lecture videos, and problem sets. However, many students found it challenging to use the recorded video materials as a primary learning resource outside of the classroom, especially when those video lessons were in particular formats. Feedback from students in the course was used to improve the usefulness of the online lessons for subsequent students. 
The experiment in transferring the curriculum to another instructor and institution (MPC) was conducted under the most challenging circumstances imaginable - a last-minute unplanned implementation of the curriculum, while it was still under revision, delivered by a community college instructor who had never taught the course previously, on top of an already full teaching load, at an institution that did not possess materials lab facilities. Despite these obstacles, students accomplished most of the learning objectives in the course, and developed an appreciation and excitement regarding the practical evaluation of materials using "real" engineering test equipment. Moreover, use of the curriculum allowed delivery of a course that was essential for the transfer eligibility of most of the enrolled students.

Unsurprisingly, some difficulties were encountered by students in both the COM and especially the MPC course. As pointed out by other researchers, the flipped student-centered approach that was used in these courses is a continuous process that must be refined based on the content, student population, methods, and instructor. ${ }^{16}$ Results from both implementations of the course suggest that the content of materials science, as compared to some other engineering courses, may require a greater level of instructor intervention during student-centered activities in order to clarify concepts and guide student understanding. This in turn may necessitate training or additional resource materials to support instructors who intend to adopt the curriculum, especially instructors who may have little or no prior experience teaching materials science. Additionally, some leveling of expectations in workload between students and the course curriculum may need to be resolved in order to improve the success of many community college students who attempt the course.

\section{Acknowledgements}

This project is supported by the National Science Foundation through the Improving Undergraduate STEM Education (IUSE) program, Award No. DUE 1430789. Any opinions, findings, and recommendations expressed in this paper are those of the authors and do not necessarily reflect the views of the National Science Foundation.

\section{REFERENCES}

1. President's Council of Advisors on Science and Technology (PCAST) (2012). Engage to excel: Producing one million additional college graduates with degrees in science, technology, engineering, and mathematics. Retrieved from http://www.whitehouse.gov/sites/default/files/microsites/ostp/pcast-engage-to-excel-final_2-2512.pdf

2. California Community Colleges Student Success Task Force (CCCSSTF). (2012). Advancing student success in California community colleges. Retrieved from

http://www.californiacommunitycolleges.cccco.edu/Portals/0/StudentSuccessTaskForce/SSTF_FinalReport_We b_010312.pdf

3. Dunmire, E., Enriquez, A., and Disney, K. (2011). The Dismantling of the Engineering Education Pipeline, Proc. 2011 Annu. Conf. ASEE.

4. Schroeder, C., Scott, T., Tolson, H., Huang, T., \& Lee, Y. (2007). A meta analysis of national research: Effects of teaching strategies on student achievement in science in the United States. Journal of Research in Science 
Teaching, 44(10), 1436-1460.

5. Smith, K., Sheppard, S., Johnson, D., \& Johnson, R. (2005). Pedagogies of engagement: Classroombased practices. Journal of Engineering Education, 94(1), 87-101.

6. Menekse, M., Stump, G., Krause, S., \& Chi, M.T.H. (2013). Differentiated overt learning activities for effective instruction in engineering classrooms. Journal of Engineering Education, 102: 346-374.

7. Krause, S., Kelly, J., Tasooji, A., Corkins, J., Baker, D., and Purzer, S. (2010). Effect of Pedagogy on Conceptual Change in an Introductory Materials Science Course.International Journal of Engineering Education, 26(4), 869-879.

8. Berrett D. (2012). How 'flipping' the classroom can improve the traditional lecture. The Chronicle of Higher Education, Feb. 19, 2012. 61.

9. Mazur, E. (2009). Farewell, Lecture? Science 323: 50-51.

10. Feisel, L., \& Rosa, A. (2005). The role of the laboratory in undergraduate engineering education. J. Eng. Educ., 94(1), 121-130.

11. Krause, S., Decker, J. C., \& Griffin, R. (2003). Using a materials concept inventory to assess conceptual gain in introductory materials engineering courses. Proceedings of the Frontiers in Education Conference.

12. Hake, Richard R. (1998) Interactive-engagement versus traditional methods: A six-thousand-student survey of mechanics test data for introductory physics courses. Am. J. Phys. 66, 64-74.

13. Jordan, W., Cardenas, H., \& O'Neal, C. B. (2005). Using a materials concept inventory to assess an introductory materials class: Potential and problems. Proceedings of the American Society for Engineering Education Conference and Exposition.

14. California Community College Chancellor's Office. (2015). Hours and Units Calculations. Retrieved from http://extranet.cccco.edu/Portals/1/AA/Credit/2015/HoursandUnitsCalculationsforCreditCoursesInstructions.pdf

15. Enriquez, A., Dumire, E., Rebold, T., Langhoff, N., and Schiorring, E. (2015). Work in Progress: Creating Alternative Learning Strategies for Transfer Engineering Programs, Proc. 2015 Annu. Conf. ASEE.

16. Connor, K. A., \& Newman, D. L., \& Deyoe, M. M. (2014), Flipping a Classroom: A Continual Process of Refinement Paper presented at 2014 ASEE Annual Conference, Indianapolis, Indiana.

https://peer.asee.org/20506 